\title{
Directional Current Breaking Capacity Requirements for HVDC Circuit Breakers
}

\author{
Geraint Chaffey, Tim C Green \\ Electrical and Electronic Engineering Department \\ Imperial College London \\ London, UK \\ Email: g.chaffey12@imperial.ac.uk
}

\begin{abstract}
Circuit breakers are expected to be a vital element within any high capacity HVDC network. This paper examines the directional current breaking capacity requirements that might be seen on a typical HVDC grid, as required for the specification of backup protection. It is shown that there is a significant difference between the peak prospective fault currents observed when the current direction is analysed. Several meshed network topologies are examined in order to evaluate and quantify the characteristics of the directional breaker requirement. Results are presented determining that both the current breaking magnitude duty and the time constraint typically associated with the DC fault are both significantly different when comparing the current direction through the breaker, which may influence future breaker design.
\end{abstract}

\section{INTRODUCTION}

Given the drive towards renewable and sustainable energy the cross-continental interconnection of power systems is highly desirable, and the most economically feasible method to provide long distance energy transfer with appropriate reliability uses meshed HVDC networks. Hybrid HVDC circuit breakers have recently been proposed that are capable of adequately protecting sensitive converter stations in $3 \mathrm{~ms}$ to $5 \mathrm{~ms}$, however their implementation on a network is still to be determined given the likely significant cost and footprint of such a device. Backup protection will be required to mitigate the risk of device failure, and this implies a need for bidirectional current breaking capability. This paper evaluates the directional current breaking capacity requirements that are observed for circuit breakers on several topologies of meshed HVDC networks.

\section{Fault Clearance And Backup Protection on HVDC SYSTEMS}

DC faults and protection are key technical challenges in the enabling of DC networks. Although fault blocking converter topologies have been proposed it is presently expected that a HVDC grid will consist largely of fault feeding converters. Converters can be considered sensitive to high currents given

The authors gratefully acknowledge the funding and support of EDF R\&D and the EPSRC through the industrial CASE scheme.

978-1-4673-7151-3/15/\$31.00 (c) 2015 IEEE the semiconductor power electronic switches within the converter. Protection systems must act quickly in order to isolate any DC-side fault given the very high rate of rise of fault current that is only limited by the inductance in the system. The converter topology commonly considered to be the most viable for a future cable-based HVDC network is the halfbridge Multi-level Modular Converter (MMC) [1], which feeds an uncontrolled fault current from the AC to the DC side in the event of a DC under-voltage. Fast fault protection is therefore required to protect the converter, isolate the fault and allow for power transfer to resume.

\section{A. Backup Protection and Directional Breaker Capacity}

Protection systems and strategies for HVDC networks are still in their infancy, and although there are many proposed schemes and methods [2]-[7], no common agreement has been reached. The two multi-terminal voltage source converter based networks in operation at the time of writing isolate a DC-side fault from the AC-side of each converter [8]. This method of fault clearance may be suitable for lower power networks, however when the power rating of an HVDC system is increased the risk of loss of in-feed to the connected $\mathrm{AC}$ systems becomes a concern. To mitigate this it is important to achieve fast fault clearance to allow power transfer to resume as quickly as possible, reducing the disturbance to the DC network and connected AC systems.

Whilst most work to date has focused on the primary protection method, there is also an interest in secondary or backup protection given that the reliability of any one $\mathrm{CB}$ or protection device cannot be absolutely guaranteed. A requirement for backup protection has been identified in the literature [9], [10], and it is further detailed that tripping all of the breakers in the surrounding area is likely to provide effective breaker failure protection [11]. Placing CBs around a node into a pre-activation 'proactive mode' could provide backup protection in the event of device malfunction [12] and CB failure modes are likely to require backup protection implementing bi-directional hybrid breakers [13]. Algorithms for coordinating backup protection have been discussed [14] and developed for high speed operation with a $3 \mathrm{~ms}$ delay on the operation of backup protection [15]. 


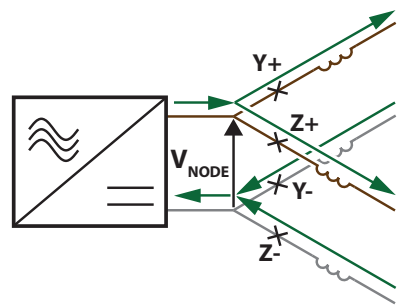

(a) Nominal Pre-fault Current

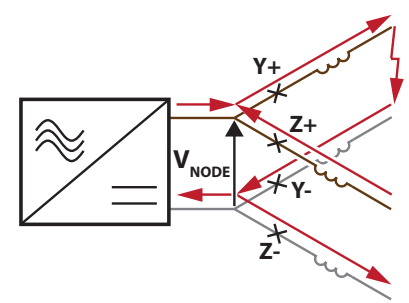

(b) DC Fault Current
Fig. 1: Fault Currents about an HVDC Network Node

A pre-fault current through a bipolar DC network node is shown in Fig. 1(a). This current direction, away from the node, is defined as 'positive' in this paper. An example of a cable fault is shown in Fig. 1(b). Whilst the largest current that a CB might be required to break is likely to be caused by a fault on the cable adjacent to the breaker (applying to breaker $\mathrm{Y}$ in this example), if the breaker nearest to the fault fails, then the fault must be isolated by other network devices. Under a cable fault condition the fault current is a combination of the current contributed by the closest converter, the cable discharge current and the current fed from remote converters. The current that flows into a node is defined as 'reverse' within this paper (as through breaker Z in Fig. 1(b)). When considering a node with a $\mathrm{CB}$ on every cable connection, backup protection must be provided by a CB that breaks the current in a direction that is only required for this backup function and in the event of a bus fault at the node.

Considering a simplistic network protection strategy, primary protection is expected to isolate the fault with the breakers nearest to the fault, $\mathrm{P}$ and $\mathrm{Q}$ in Fig. 2(a). In the event of a breaker failure, backup protection must isolate the fault. At a network node without a converter, this is likely to require all of the breakers about the local node to open, isolating the fault from the remainder of the network as shown in Fig. 2(b). Here only requiring communication between breakers at a local node allows for a timely and appropriate backup protection. At a network node with a converter, protection would also be required such that the converter does not continue to feed current into the fault this is likely to be isolated by the AC-side circuit breakers of the converter Fig. 2(c). Once the current in the isolated network segments falls to zero it would be expected that disconnectors would isolate the faulted line and the remaining network segments would then be re-energised.

Whilst when considering other converter topologies a different or more relaxed protection scheme may be appropriate [7], [16], [17], the results discussed in the following sections apply in part to each of the known published protection schemes for meshed HVDC cable networks implementing fault-feeding converters and DC CBs [2]-[5], [7].

\section{B. DC Circuit Breaker Implementation}

Presently there are no full-scale HVDC Circuit Breakers $(\mathrm{CB})$ in operation for purposes of fast fault isolation, however some high power demonstrators exist. There are several prominent proposed designs; resonant CBs which are able to act in the $5 \mathrm{~ms}$ to $30 \mathrm{~ms}$ time-scale [18], [19], and hybrid CBs which are capable of acting in the $3 \mathrm{~ms}$ to $5 \mathrm{~ms}$ time-scale [20]-[22]. The peak breaking current of the highest rated known prototypes are $9 \mathrm{kA}$ and $15 \mathrm{kA}$ [20], [22].

Whilst it is expected that the resonant style CB would have a significantly smaller footprint and would be less complex, the technology has not yet been proven for high power fast fault isolation. Conversely, the hybrid $\mathrm{CB}$ has demonstrated capability for very fast operation, however this comes at significant cost and complexity. Several hybrid topologies suggest a bi-directional and symmetrical CB [20], [22], typically consisting of combinations of anti-series semiconductor devices whilst the highest rated prototype at the time of writing implements parallel semiconductors [22], enabling a higher current breaking capability. If current breaking capacity is only required in one direction, then there is no longer a requirement for anti-series semiconductors and the number of devices could be reduced. Alternatively if there is a significantly diminished requirement for current breaking capacity it may be possible to reduce the capacity of the semiconductor devices in one direction or use a different breaker technology for this duty. Any topology implementing parallel devices may achieve a reduction in parallel paths for one current direction, and any energy dissipation required by varistor elements would be less than when compared to the worst case fault in the forward direction.

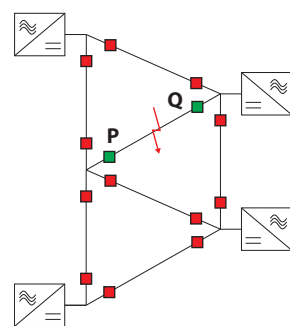

(a) Primary Protection

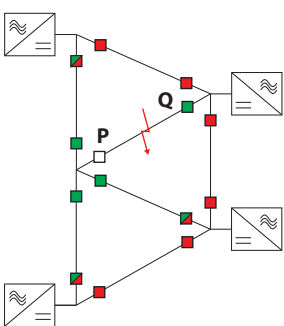

(b) Breaker P Failure

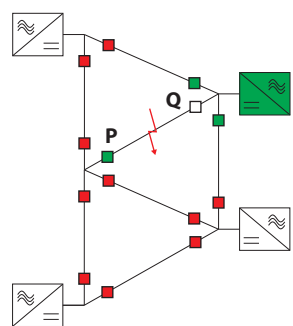

(c) Breaker Q Failure
Fig. 2: Examples of Backup Protection Requirements on a Meshed Network (Red Indicates Closed Breaker, Green Indicates Open Breaker or Isolated Converter)

\section{Analysis of DC Low Impedance Fault CuRRENTS}

In order to evaluate the fault response of HVDC converters and cables on a network, time domain simulation has been conducted in which networks consisting of MMCs and transmission cable models have been exposed to short circuit fault conditions.

\section{A. Modelling Methodology}

Each MMC has been modelled using the ARTEMIS model [23] with the parameters in Table I. The arm inductors have been sized to limit the fault current in the event of a fault at the converter terminal. Each converter arm is modelled 


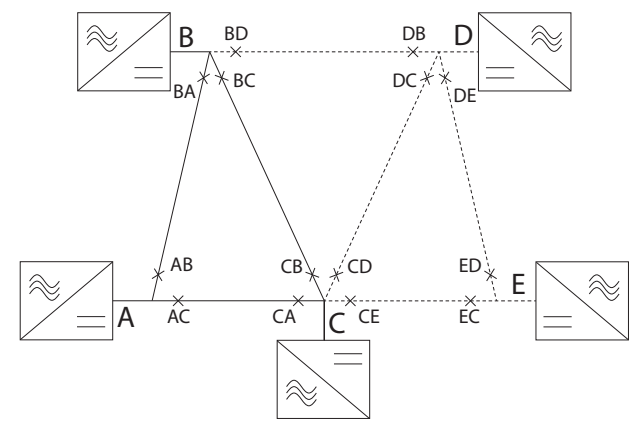

Fig. 3: Three Terminal Network (solid lines), and Five Terminal Network (all lines), in which Each Line Represents a Bipolar Cable Arrangement with Breakers and Each Converter Represents an MMC

with 75 sub-modules (SM), allowing for representation of the converter dynamics whilst maintaining a reasonably low computational burden. $525 \mathrm{kV}$ XLPE cables are modelled, representing the highest power cable that is commercially available at the time of writing [24], and power electronic technology is approaching the power ratings required to maximise power transfer using MMC topologies [25]. Cables have been modelled using the wideband (frequency dependent phase model) cable model included in the ARTEMIS blockset [26] within the Matlab/Simulink environment. Further detail on the converter and cable modelling methodology is presented in [16]. Fig. 1 shows the configuration at each network node, consisting of a $\mathrm{CB}$ and associated current limiting inductor at each end of each cable. In common with proposed breaker and protection schemes, e.g. [20], [27], a $100 \mathrm{mH}$ inductor has been included at each end of each cable to limit the rate of rise of fault current. Low impedance DC faults have been modelled as a pole-to-pole $0.5 \Omega$ resistance that is switched into circuit at the point of fault inception.

TABLE I: Simulation Parameters

\begin{tabular}{|c|c|}
\hline \multicolumn{2}{|c|}{ Converter Parameters } \\
\hline $\mathrm{V}_{\mathrm{DC}}$ & $\pm 525 \mathrm{kV}$ \\
$\mathrm{I}_{\mathrm{DC}}\left(\mathrm{I}_{\mathrm{BASE}}\right)$ & $2260 \mathrm{~A}$ \\
$\mathrm{~N}_{\mathrm{SM}}$ & 75 \\
$\mathrm{~L}_{\mathrm{PHASE}}$ & $0.1 \mathrm{pu}$ \\
$\mathrm{L}_{\mathrm{ARM}}$ & $0.2 \mathrm{pu} \dagger$ \\
$\mathrm{C}_{\mathrm{DC}}$ & $0 \mu \mathrm{F}$ \\
\hline \multicolumn{2}{|c|}{ Network Parameters } \\
\hline $\mathrm{Cable}_{\mathrm{BRK}}$ & XLPE $3000 \mathrm{~mm}^{2} \mathrm{Cu}$ \\
$\mathrm{L}_{\mathrm{BR}}$ & $100 \mathrm{mH} / \mathrm{pole} \dagger$ \\
$\mathrm{AC}_{\mathrm{SCR}}$ & $15 \dagger$ \\
\hline
\end{tabular}

$\dagger$ Base case parameter, varied in sensitivity study

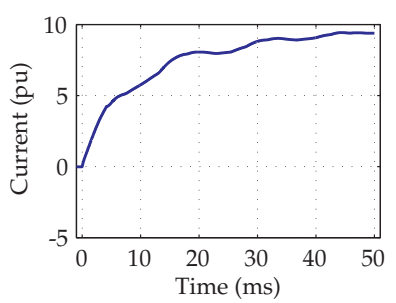

(a) Breaker BC

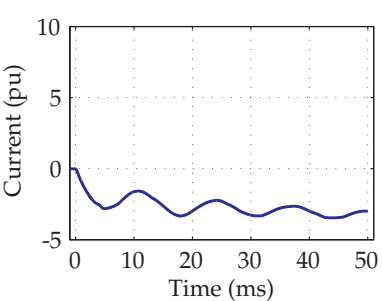

(b) Breaker BA
Fig. 4: Fault Currents Observed at the Breaker on a Symmetrical Three Terminal Network for a Fault at the end of Cable B-C

\section{B. Converter Control, Protection and Fault Response}

Power flows are controlled by modulating power references for the converters across the network, in which a positive power reference indicates power transfer from the AC system to the DC system. Converter A controls the network voltage. In order to provide over-current protection for the lower diode in each MMC half-bridge SM, when a $1.5 \mathrm{pu}$ arm current is detected the IGBTs in each SM are blocked and bypass thyristors are enabled. Each converter station has individual protection controls that act on localised measurements and do not rely on communication with other converters or breakers on the network.

\section{DC Fault Response}

In order to evaluate breaker requirements, preliminary results from a three terminal network have been examined. Evaluating the converter and network response to a cable fault at the breaker terminal it is observed that the prospective forward breaker current (shown as positive on all figures) at breaker BC quickly rises, Fig. 4(a). The DC fault causes a voltage drop across the network, putting the MMCs into uncontrolled rectification. This challenging fault scenario is the key driver behind hybrid CB development. Now examining the breaker response of breaker BA on an adjacent cable A-B, the reverse breaking capability requirement can be analysed. It is shown in Fig. 4(b) that although the breaker current in the reverse direction (shown as negative on all figures) is not insignificant, the rate of rise of fault current is considerably slower and the peak current is lower compared to the forward current in breaker BC. This is due to the additional inductance of the cable and breaker inductors limiting the rate of rise of current and the additional resistance of the cable limiting the peak current. The local converter also feeds the majority of the fault current during a terminal fault. The disparity between forward and reverse capacity requirements will be further examined in the following sections.

\section{Evaluation of Directional Breaker CAPACity REQUIREMENT}

The converter and network parameters in Table I are taken as a base case for each simulation scenario where worst 


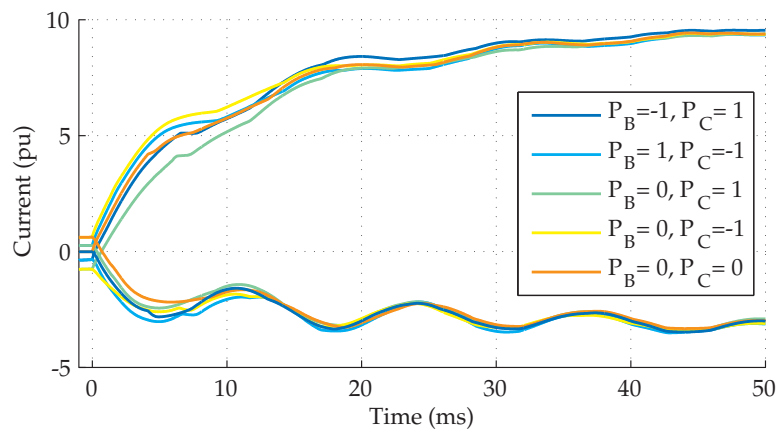

Fig. 5: Three Terminal Symmetric Network: Fault Currents at Breaker BC Varying Pre-fault Power Flow Conditions

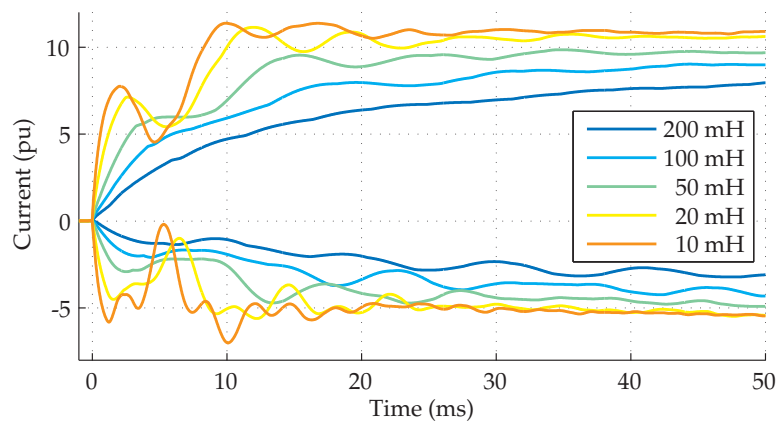

Fig. 6: Three Terminal Symmetric Network: Breaker Fault Currents Varying All Fault Current Limiting Inductors

case values for each parameter are chosen to evaluate the prospective reverse breaker current. A sensitivity study on the impact of these factors is undertaken in the following sections, in which several parameters are individually examined to determine the impact on the reverse current characteristic. Unless otherwise stated fault studies are evaluated under zero power flow conditions. As a reference for comparison the peak prospective forward current is also shown in every case. It should be noted that the two known hybrid breaker prototypes have current breaking capacities of $4.0 \mathrm{pu}$ and $6.6 \mathrm{pu}$.

\section{A. Three Terminal Symmetric Network}

In order to evaluate the directional current requirements of a breaker under a variety of network conditions a three terminal symmetric network, Fig. 3, has been evaluated with parameters as shown in Table II. The symmetry of the network enables the examination of selected network parameters whilst minimising the effect of cable length on the results.

1) Pre-fault Power Flow: The forward and reverse fault currents have been examined under several pre-fault power flow conditions. Power references are examined that evaluate the breaker currents such that each breaker on the network experiences a fault under both maximum positive $(+1 \mathrm{pu})$ and maximum negative $(-1 \mathrm{pu})$ pre-fault current conditions. For each pre-fault power flow condition a simulation study has been conducted for two fault locations; a fault at the terminal

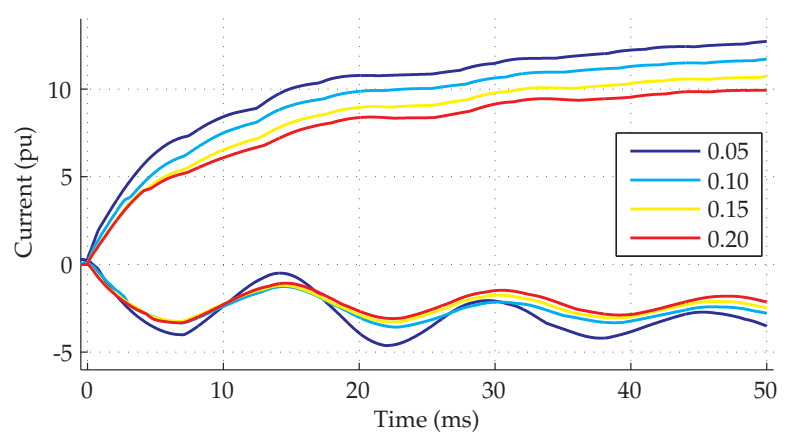

Fig. 7: Three Terminal Symmetric Network: Breaker Fault Currents Varying the Per-unit Converter Arm Inductance

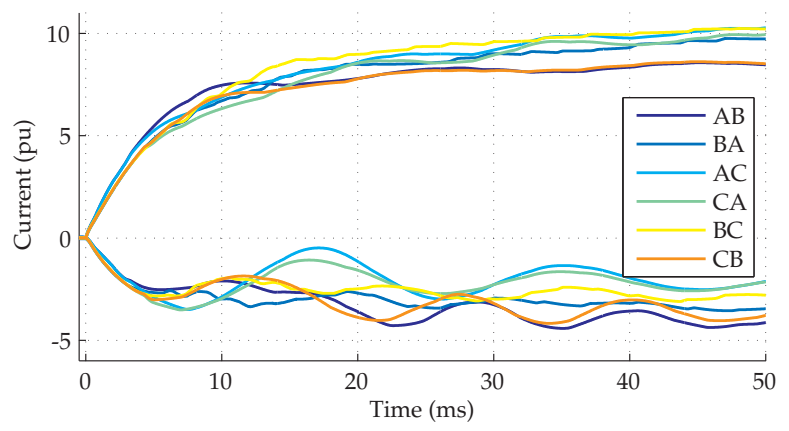

Fig. 8: Three Terminal Asymmetric Network: Currents for a Terminal Fault Adjacent to Each Breaker

of the breaker under examination and a fault at the terminal of the adjacent breaker at the same node.

The fault currents through breaker BC are shown in Fig. 5. It can be observed that the forward fault current reaches $5.1 \mathrm{pu}$ in $5 \mathrm{~ms}$ and rises to $6.2 \mathrm{pu}$ in $10 \mathrm{~ms}$. When examining the reverse current whilst $3.0 \mathrm{pu}$ is reached in $5 \mathrm{~ms}$, the current falls to $2.1 \mathrm{pu}$ in $10 \mathrm{~ms}$. A current oscillation is observed in the cables adjacent to the fault at the resonant frequency of the cable inductance and capacitance and the breaker inductance, therefore the frequency of oscillation is dependent on the cable length. It is shown that in the forward direction the peak breaking current of the highest known capacity breaker (6.6 pu) is exceeded in $11 \mathrm{~ms}$, whilst in the reverse direction the peak current does not reach $6.6 \mathrm{pu}$ in the $50 \mathrm{~ms}$ following the fault.

2) Circuit Breaker Inductance: Fig. 6 shows the observed fault currents with variation in series inductance. When examining lower circuit breaker inductances, the fault current in both directions through the breaker exceeds the current rating of the highest capacity hybrid breaker in the first milliseconds following fault inception. Simulation of higher breaker inductances exhibits a slower rate of rise of current in both the forward and reverse directions. Throughout all tests the reverse breaker current remains less severe than the forward current. 


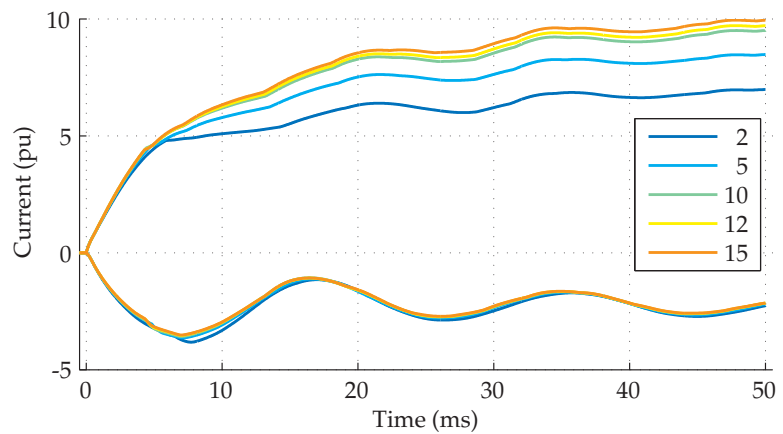

Fig. 9: Three Terminal Asymmetric Network: Currents at Breaker CA Under Varying AC-side Short Circuit Ratio Conditions at Converter $\mathrm{C}$

3) Converter Arm Inductance: A certain amount of arm inductance is required to control the arm current in an MMC, however this component is typically oversized to limit the current in the event of a DC-side fault. In the base simulation case a typical value of $0.2 \mathrm{pu}$ has been chosen to limit the current in the event of a fault at the converter terminal. Fig. 7 shows the impact of reducing this arm inductance. It can be observed that although there is a significant impact on the rate of rise of forward current the reverse current is not significantly affected.

\section{B. Three Terminal Asymmetric Network}

To determine the dependence of the reverse current characteristic on the length of the connected cables, fault studies have been conducted on an asymmetrical three terminal network, Fig. 3, with the parameters listed in Table I. This aims to provide a more representative model of a small meshed network.

1) Line Length: Given the significant capacitance and inductance of cable transmission mediums the length of cables can play a significant role in the fault currents experienced on a network. Fig. 8 examines the breaker fault currents during a fault at the terminal at each breaker, in which the influence of line length is clearly shown. The forward breaker currents are impacted by the length of the other cables about the same node, whereas the reverse fault current characteristic depends on the length of the cable being protected by the breaker. In

TABLE II: Line Lengths

\begin{tabular}{|c|ccc|}
\hline & 3T Sym & 3T Asym & 5T \\
\hline AB & 200 & 200 & 200 \\
AC & 200 & 550 & 550 \\
BC & 200 & 85 & 85 \\
BD & - & - & 350 \\
CD & - & - & 220 \\
CE & - & - & 300 \\
DE & - & - & 120 \\
\hline
\end{tabular}

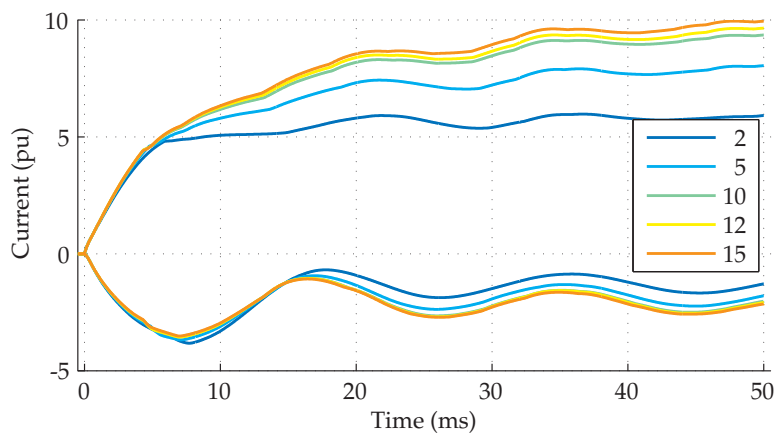

Fig. 10: Three Terminal Asymmetric Network: Currents at Breaker CA Under Varying AC-side Short Circuit Ratio Conditions at All Converters
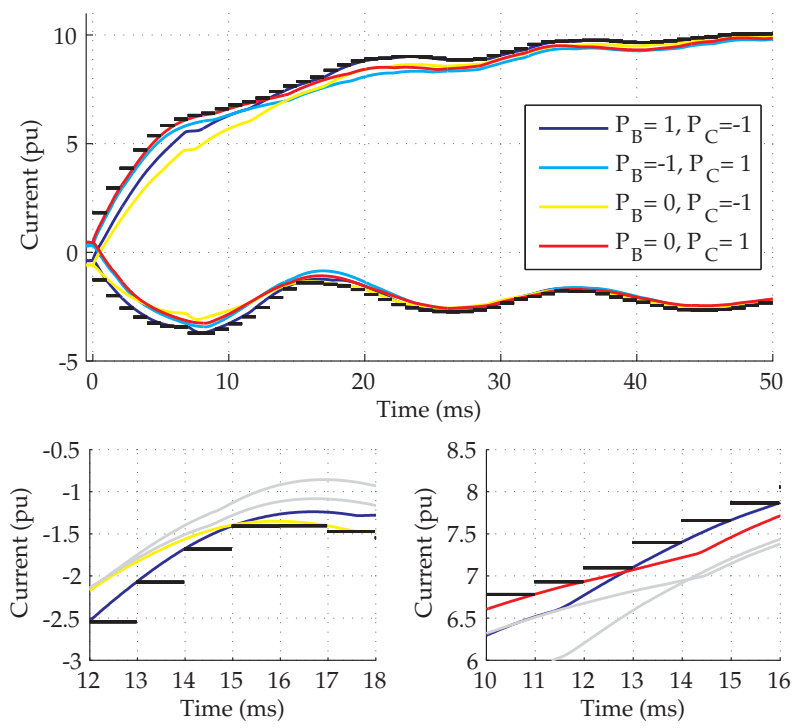

Fig. 11: Three Terminal Asymmetric Network: Currents at Breaker CA under Varying Pre-fault Power Flow Conditions (Maximum and Minimum Indicated with $1 \mathrm{~ms}$ Resolution)

the first milliseconds the largest reverse current is observed from the longest line due to the larger stored energy in the line, however in the $10 \mathrm{~ms}$ to $30 \mathrm{~ms}$ range the largest reverse current is observed on the shortest cable due to the lower impedance limiting the fault current from remote converter stations.

2) AC-side Short Circuit Ratio: The Short Circuit Ratio (SCR) of the connected AC systems plays a significant role in the fault current observed on the DC network. Whilst many HVDC converters are likely to be connected to weak AC systems, it is also feasible that a converter would be connected to a very strong $\mathrm{AC}$ system, therefore the impact of this parameter must be evaluated.

Evaluating the influence of the SCR at just converter C, Fig. 9, it is observed that whilst the initial rate of rise of fault current is similar for each simulation, the converter fault 


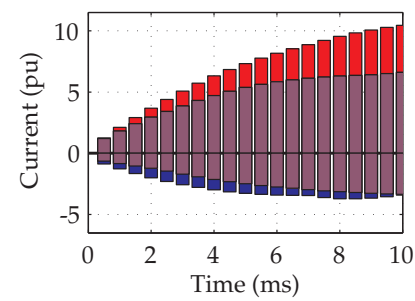

(a) $\mathrm{CA}$

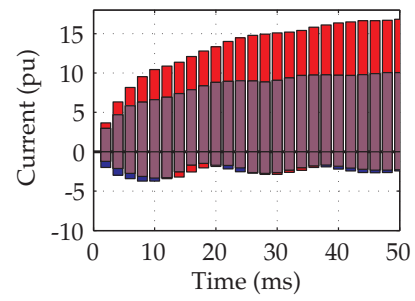

(e) $\mathrm{CA}$

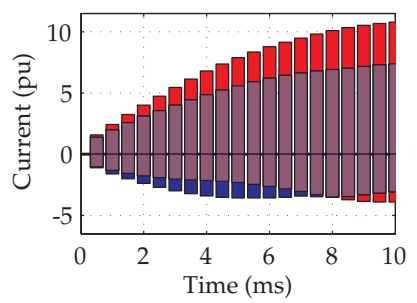

(b) $\mathrm{CB}$

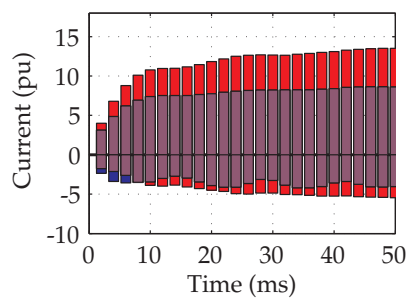

(f) $\mathrm{CB}$

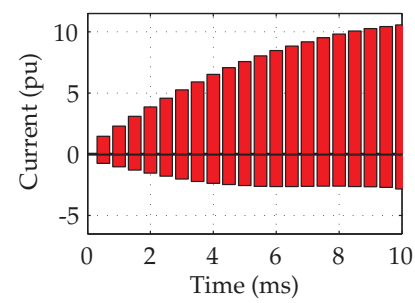

(c) $\mathrm{CD}$

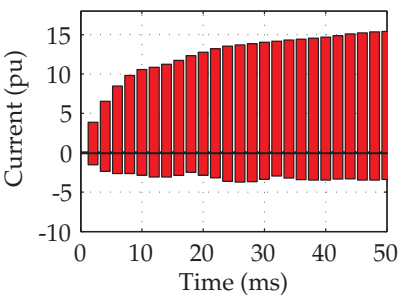

(g) $\mathrm{CD}$

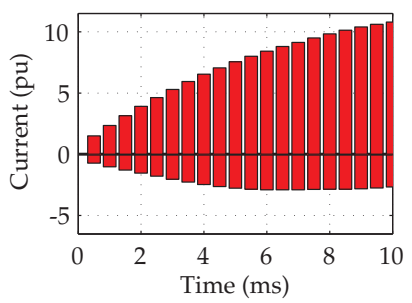

(d) $\mathrm{CE}$

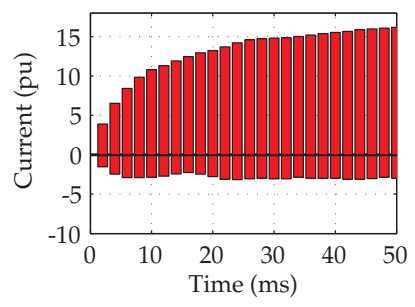

(h) $\mathrm{CE}$

Fig. 12: Aggregated Peak Breaker Current Capacity Requirements: Five Terminal Network (Red and Purple) and Three Terminal Network (Blue and Purple); $10 \mathrm{~ms}$ following Fault Inception (Top Row, $0.5 \mathrm{~ms}$ Resolution) and $50 \mathrm{~ms}$ following Fault Inception (Bottom Row, 2 ms Resolution)

current at the local node is limited by the AC system. The impedance between the remote nodes and the fault remains constant therefore there is little deviation in the reverse current.

Evaluating the effect of the SCR of all the converters on the network, Fig. 10, it is shown that the peak fault current is significantly constrained when the available AC-side power is restricted, and therefore the peak forward current is reduced. The reverse current is slightly reduced for low SCR networks.

3) Pre-fault Power Flow: The impact of the pre-fault power flow on the reverse current characteristic is now evaluated on the asymmetric network. The pre-fault power flow has an impact on the magnitude of the oscillations on the non-faulted cables, therefore to provide a peak directional current profile an aggregation has been made of the results by taking the maximum current from all results in $1 \mathrm{~ms}$ time divisions, as shown in Fig. 11.

\section{Comparison with Five Terminal Network}

In order to better evaluate the difference between the forward and reverse breaker currents, a five terminal meshed network has been investigated. The most influential result from the three terminal network studies, the pre-fault power flow, will be subject to a parameter sweep in the following analysis. All other parameters are fixed to the expected worst case values presented in Table I. The peak fault currents for each breaker location are then aggregated such that over each time period $(0.5 \mathrm{~ms}$ or $2 \mathrm{~ms})$ the peak forward and reverse currents are calculated for each breaker, as shown in Fig. 11. In this manner a peak breaker current profile is formed, and it is proposed that this may be used to evaluate a circuit breaker topology and rating for application to a particular network location.
For berevity only node $\mathrm{C}$ of the network has been presented; by examining a node with 4 adjacent cables the results from the part of the network that is topologically least similar to a smaller network are shown. The peak directional breaker current requirements have been evaluated for both three terminal and five terminal networks. Fig. 12 shows the aggregated results, in which the results from the three terminal network have been overlaid for comparison. First evaluating the $10 \mathrm{~ms}$ following the fault, Fig. 12(a-d), it is shown that the five terminal network has a larger forward current characteristic, due to the greater fault in-feed from cable capacitance discharge and remote converter current contribution. Examining the $50 \mathrm{~ms}$ following the fault, Fig. 12(e-h), the influence of line length is clear, in particular in the characteristic of breaker $\mathrm{CB}$ (protecting the $85 \mathrm{~km}$ line $\mathrm{B}-\mathrm{C}$ ) in which the forward current is increased due to the increased current in-feed from remote converters. The reverse current is increased due to the comparatively low impedance between the fault and remote converter stations.

In the forward direction, the initial current rises similarly on both the three and five terminal scenarios, however the current continues to rise on the five terminal network given the larger infeed from the other additional converter stations. In general the same trends can be observed on the five terminal network that have been seen from the three terminal network studies, and throughout each study the reverse current characteristic is significantly less severe than the forward characteristic.

\section{CONClusion}

The directional characteristic of the HVDC circuit breaker current has been examined, showing that there is significant disparity between the breaker duties dependent on the current direction at the breaker, both in terms of peak current breaking 
capacity and the time the breaker may be required to operate in. Based on these results it may be possible to reduce the number of semiconductor devices for some proposed topologies of hybrid DC circuit breakers. In particular the reduced reverse current breaking requirement may have implications for circuit breaker design and protection system selectivity timings in future HVDC networks.

\section{REFERENCES}

[1] N. Ahmed, S. Norrga, H.-P. Nee, A. Haider, D. Van Hertem, L. Zhang, and L. Harnefors, "HVDC SuperGrids with modular multilevel converters 2014; The power transmission backbone of the future," in Systems, Signals and Devices (SSD), 2012 9th International Multi-Conference on, March 2012, pp. 1-7.

[2] C. D. Barker and R. S. Whitehouse, "An alternative approach to HVDC grid protection," in AC and DC Power Transmission (ACDC 2012), 10th IET International Conference on, Dec 2012, pp. 1-6.

[3] A. Adamczyk, C. D. Barker, and H. Ha, "Fault detection and branch identification for HVDC grids," in Developments in Power System Protection (DPSP 2014), 12th IET International Conference on, March 2014, pp. 1-6.

[4] J. Sneath and A. D. Rajapakse, "Fault Detection and Interruption in an Earthed HVDC Grid using ROCOV and Hybrid DC Breakers," Power Delivery, IEEE Transactions on, vol. PP, no. 99, pp. 1-1, 2014.

[5] W. Leterme and D. Van Hertem, "Classification of Fault Clearing Strategies for HVDC Grids," in Across borders - HVDC systems and markets integration: CIGRE Lund, 2015.

[6] M. Hajian, L. Zhang, and D. Jovcic, "DC Transmission Grid With Low-Speed Protection Using Mechanical DC Circuit Breakers," Power Delivery, IEEE Transactions on, vol. 30, no. 3, pp. 1383-1391, June 2015.

[7] C. Barker, R. Whitehouse, A. Adamczyk, and M. Boden, "Designing fault tolerant HVDC networks with a limited need for HVDC circuit breaker operation," B4-112, CIGRE, 2014.

[8] H. Rao, "Architecture of Nan'ao multi-terminal VSC-HVDC system and its multi-functional control," Power and Energy Systems, CSEE Journal of, vol. 1, no. 1, pp. 9-18, March 2015.

[9] J. 13/14.08, Technical Brochure 114: Circuit-Breakers for Meshed Multiterminal HVDC Systems. CIGRE, 1997.

[10] B. Berggren, J. Wang, J. Pan, K. Srivastava, K. Linden, and R. Nuqui, "Fault protection of HVDC transmission lines," Jun. 10 2014, uS Patent 8,749,933. [Online]. Available: https://www.google.com/patents/US8749933

[11] W. B4.52, Technical Brochure 533: HVDC Grid Feasability Study. CIGRE, 2013

[12] J. Häfner and B. Jacobson, "Proactive Hybrid HVDC Breakers-A key innovation for reliable HVDC grids," Proc. of Cigré Bologna, Paper, vol. 264, 2011.
[13] J. Sneath, "Grounded HVDC Grid Line Fault Protection Using Rate of Change of Voltage and Hybrid DC Breakers," Master's thesis, The University of Manitoba, 2014.

[14] J. Descloux, "Protection contre les courts-circuits des réseaux à courant continu de forte puissance," Ph.D. dissertation, Université de Grenoble, 2013.

[15] W. Leterme, S. Azad, and D. Van Hertem, "Fast Breaker Failure Backup Protection for HVDC Grids," International Conference on Power Systems Transients, 2015.

[16] G. Chaffey and T. C. Green, "Reduced DC Circuit Breaker Requirement on Mixed Converter HVDC Networks," in PowerTech (POWERTECH), 2015 IEEE Eindhoven, June 2015.

[17] D. Jovcic, M. Taherbaneh, J.-P. Taisne, and S. Nguefeu, "Offshore DC Grids as an Interconnection of Radial Systems: Protection and Control Aspects," Smart Grid, IEEE Transactions on, vol. 6, no. 2, pp. 903-910, March 2015.

[18] K. Tahata, S. E. Oukaili, K. Kamei, D. Yoshida, Y. Kono, R. Yamamoto, and H. Ito, "HVDC circuit breakers for HVDC grid applications," in $A C$ and DC Power Transmission (ACDC 2015), 11th IET International Conference on, Feburary 2015, pp. 1-6.

[19] T. Eriksson, M. Backman, and S. Halén, "A low loss mechanical HVDC breaker for HVDC grid applications," Proc. Cigré Session, Paris, France, 2014.

[20] M. Callavik, A. Blomberg, J. Häfner, and B. Jacobson, "The Hybrid HVDC Breaker," ABB grid system, Technical paper Nov, 2012.

[21] W. Grieshaber, J.-P. Dupraz, D. L. Penache, and L. Violleau, "Development and test of a $120 \mathrm{kV}$ direct current circuit breaker," CIGRE session 2014,2014

[22] SGRI, "SGRI launches world's first 200kV DC circuit breaker," 2015.

[23] H. Saad, C. Dufour, J. Mahseredjian, S. Dennetire, and S. Nguefeu, "Real Time simulation of MMCs using the State-Space Nodal Approach," International Conference on Power Systems Transients (IPST2013) in Vancouver, Canada July 18-20, 2013, 2013.

[24] A. Gustafsson, M. Saltzer, A. Farkas, and M. J. Hossein Ghorbani, Tobias Quist, "The new 525kV extruded HVDC cable system," $A B B$ Grid Systems, Technical Paper, 2014.

[25] P. Lundberg, A. Gustafsson, and M. Jeroense, "Recent advancements in HVDC VSC systems," in Across borders - HVDC systems and markets integration: CIGRE Lund, 2015.

[26] O. Ramos-Leanos, J. Naredo, J. Mahseredjian, C. Dufour, J. GutierrezRobles, and I. Kocar, "A Wideband Line/Cable Model for Real-Time Simulations of Power System Transients," Power Delivery, IEEE Transactions on, vol. 27, no. 4, pp. 2211-2218, Oct 2012.

[27] C. D. Barker and R. S. Whitehouse, "An alternative approach to HVDC grid protection," in AC and DC Power Transmission (ACDC 2012), 10th IET International Conference on, Dec 2012, pp. 1-6. 